\title{
A MONISTIC CONCEPTION OF CONSCIOUSNESS
}

IN REPLY TO MR. AYTON WILKINSON'S ARTICLE ON "WILLFORCE” AND MR. MONTAGUE'S "ARE MENTAL

PROCESSES IN SPACE?"

LL religious and philosophical problems are centered
in the soul-conception, for the nature of the world
and our attitude toward it, our conduct and ethical prin-
ciples, the significance of life, and any other issue of prac-
tical consequence, will depend upon the nature of our own
being. So it is quite natural that men of a serious temper
are much concerned about psychological problems, because
they feel that a wrong psychology will warp their philo-
sophical system and twist their ethics so as to render it an unsafe guide through life. On the other hand, however, we find that men who start from wrong principles correct their mistakes through practical motives. They grope in the dark and though they make a wrong start, finally reach the right conclusions because their conscience is properly attuned to the universe and they are therefore able to adjust themselves properly and find their true bearings.

We published an article by Mr. Wilkinson in The Monist of January, 1899 , but he insists that in an editorial reply at that time, his presentations were completely misunderstood. We must leave the decision of this question to our readers, but if we were mistaken, we will now make up for our error by giving him another opportunity to ex- 
plain his views, and we do this the more gladly since his essay touches the salient point of the question.

We do not share his views, but we have tried and abandoned them, and believe that no thinker should pass them by without considering them both earnestly and thoroughly. Though we can not accept Mr. Wilkinson's view of the soul, including also his theology and philosophy, we grant that his arguments are well taken, as well as any man of science who would agree with him could present them.

The question of the soul and its nature is the basic problem of our world-conception, and attempts have constantly been made to give to the soul an exceptional position in the universe, to let it be a force, or a power, or an entity, possessed of sundry mysterious faculties which are capable of mechanically interfering with natural things, without itself being at the same time mechanical or purely physical. Mr. Wilkinson pursues this same object but no longer relying on metaphysical considerations, as do his predecessors, he modernizes the issue and would make his interpretation of the soul plausible to a man of science.

There are two philosophical world-conceptions, which are diametrically opposed to each other, and we will call one the materialistic, and the other the spiritualistic view. The former attempts to establish monism, the latter openly declares that monism breaks down and we have to accept either a dualism or a pluralism. The former view, that of materialistic monism, proposes to explain the origin of the soul from the rest of the universe, which represents itself to our senses as matter in motion. The latter view, that of spiritualistic dualism or pluralism, recognizes the soul as a mysterious entity, and the question is only whether we have a contrast of two things (spirit and matter) implying dualism, or whether our soul is an irre- 
ducible unit in itself. The latter view inevitably leads to pluralism.

If materialistic monism is correct, it is commonly claimed that consciousness is merely a manifestation of matter; that all actions are determined by the irrefragable law of necessity, and that consequently man is not responsible for his deeds. Accordingly freedom of the will would be an illusion, and ethics a vagary. There would be no law that any one would have to respect and the survival of the fittest would be the only norm of human conduct. It is obvious that science possesses a monistic trend, and wherever we enter into details of physics, physiology, chemistry,-even into zoology and anthropology, including psychology, the monistic conception is verified and has led to the assertion that modern psychology is a psychology without a soul.

In contrast to this materialistic monism, a large class of thoughtful men have embraced the opposite horn of the dilemma, and believe in the existence of a separate soulentity. They accept scientific statements as limited to certain spheres of existence, but believe that the soul, or generally speaking the spiritual factor of life, constitutes an exception to the rule of universal causation; and thus they force upon us the theory of dualism or perhaps pluralism. The main problem to men of this class consists in reconciling the strict methods of science, which after all are unequivocally monistic, to their dualistic or pluralistic views. This being impossible, their philosophy will either be mysticism, agnosticism or pragmatism.

Mr. Wilkinson's explanation is especially fascinating because it is unusually tinged with a recognition of the monistic principle of science, and at the same time is in accord with a dualistic theology which re-establishes the conception of a God as creator without denying the principles of science; and yet we must object to Mr. Wilkin- 
son's argument because a truly consistent monistic view is after all superior, and avoids the contradiction of dualism in which the logical inferences of his views become implicated.

We wish to state from the start, however, that our monism is different from the common monistic conception which we have characterized as materialistic monism. In so far as we recognize many points on which the main arguments of dualism are based, we take a middle ground between the two views, and we would emphasize the fact that we are far from denying the significance of the soul. We accept the truth that the soul is the master of the destiny of man. It is the principle of direction, and moral responsibility exists as a fact to be accounted for, not to be doubted or explained away. Materialistic monism which practically denies the soul is one-sided, and we have so far characterized it as a pseudo-monism which might be called henism, since it is a theory of unification which, instead of presenting an impartial view of the whole universe, artificially reduces contrasts by denying either opposite, and thus lacks completeness because in contemplating one side it ignores the other.

Consciousness is a fact which no one can deny: and it is the most wonderful fact within the range of our experience. It is not less wonderful for the reason that it is really the fabric of which the soul is woven, but the peculiarity of consciousness is that it is not a material thing, not a substance, not even a permanent existence, nor an entity of any kind, but a function. It is fleeting; it originates and disappears; it varies; it grows stronger and weaker; in sleep it is reduced; and in death becomes to all appearance entirely extinct. Its contents, too, change constantly, and there is scarcely an instant in our lives in which we have the same thought repeated. Consciousness is closely interwoven with the sense-impressions of touch, 
motor sensibility, taste, smell, and especially sight; and our soul weaves out of these sense-impressions, a higher world of abstract thought most of which is more or less accompanied by sentiment, i. e., an emotional element partly pleasurable, partly painful, partly indifferent.

Consciousness is a phenomenon radically different from the world of material objects as which our sense-impressions represent our surroundings including even our own body. It can be characterized as awareness; for consciousness is that state which makes us know of our own existence, and, as simple as this seems to be, we repeat it is the most wonderful fact within the range of our entire experience and stands in contrast to the general features of the objective world in which we move.

Consciousness is a complicated state and the elements into which we can analyze it are called feelings. Feelings in their turn are not ultimate units, but consist of subconscious states of irritation and these again depend upon highly complex conditions in the organization of living substance. Then we lose our track in the realm of the unconscious.

We must recognize that our experience shows us a contrast of two states of things. In the first place, the world as it confronts our senses; its general features are matter and motion, and those portions of it which in the general flux show a certain stability we call objects. Secondly, the world of which we feel our own awareness, consisting of sensations, sentiments, thoughts and volitions. The former is the world of objectivity and the latter is called subjective.

If the domains of objectivity and subjectivity were two isolated spheres, dualism would have to be regarded as incontrovertible, but subjectivity and objectivity are so interlinked that there is no subjective state which does not imply an objective reality of some kind. Hand touches hand, and what seems to us subjective feeling is at once repre- 
sented by our senses as an objective condition in our limbs, and so we come to the conclusion that our corporeal being is part and parcel of the objective world which we represent to lie outside of ourselves. We can not doubt that our body constitutes a part of the entire cosmos; we grow from it, we are nourished by it, and after the dissolution of death the constituents of the body return to it. At the same time we notice that our states of consciousness are dependent upon the influences of objective existence, yea the subjectivity of our consciousness can only be explained as due to the organization which has naturally arisen in the course of the evolution of life. We are compelled to view the contrasts of subjectivity and objectivity under a monistic system which conceives them as two sides or phases of the same reality; subjectivity is the inner state, as existence is in itself ; while objectivity is the external or outer aspect, as anything that exists presents itself to other things. In itself everything that exists is a subjective state of selfness: which may be unconscious, subconscious, or conscious, but if approached from the outside it is an object, i. e.. a material body in motion.

Having in previous publications, especially in The Soul of Man and in Whence and Whither, explained with sufficient attention to detail, how subjectivity, which in its elements is potential feeling, develops by organization into consciousness; and how irritability changes into mind in the measure that feelings acquire representative value, we can limit ourselves here to the issues raised by Mr. Wilkinson who looks upon consciousness as possessed of the intrinsic power to create energy from nothing out of its own mysterious resources. Mr. Wilkinson bases his contention upon the fact that consciousness imparts direction to our movements, and we do not deny its directive faculty. It might seem then that since consciousness possesses no energy it must be capable of generating it, and that is indeed 
Mr. Wilkinson's conclusion. He is fully aware of the scientific difficulty of assuming that something should be produced from nothing, but he finds much satisfaction in the thought of rehabilitating in this way the conception of a personal and a conscious God who has created the world from nothing, merely by the force of his will.

We grant that mind is a directing faculty, and we also know that consciousness is commonly and rightly held to be void of motor power. But these two concessions might seem contradictory and need some explanation.

We must consider that all our ideas are abstractions. When we speak of consciousness we mean consciousness and not motion. Accordingly we understand that consciousness does not move, and that motion does not become consciousness. When we speak of matter we mean all those features which are common to the objects of our senses. There is no material which would be matter and nothing but matter, or in other words the idea of matter in itself is a fiction, and so is the idea of consciousness in itself. So far as we know, consciousness is closely linked with motion of some kind and every thought which we think must be the internal state of a physiological commotion in the nervous substance of our brain. Accordingly the actual process of the function of consciousness presupposes an analogous objective process of cerebral activity, which is a mechanical process of a definite discharge of energy. There is no consciousness by itself alone. We make this explicit statement because the lack of its cognisance has produced infinite confusion among psychologists and philosophers from time immemorial.

The ancient philosophers of India represented the soul as a blind man possessed with muscular motor power carrying a lame man in possession of his full eye-sight. The seeing man could give directions to the man who carried him but he could not walk himself, and the blind man could 
walk but could not find his bearings. This simile is based upon the assumption that abstract ideas exist by themselves. Consciousness is supposed to be the lame man who can see, and our motor power with all the energy of our feet and hands including the energy stored in our brain is compared to the blind man who can move about but who is unable to see. Philosophers even of modern times have taken the simile literally and seriously by insisting that consciousness is a mere spectator; for it can not move, and our motor powers comprising all the energy at our disposal can not become conscious. This is true if we understand by consciousness the abstract idea of consciousness or consciousness in itself, and by energy all our motor power to the exclusion of any thing else. But it is not exactly true if we consider the actualities from which these two abstract ideas have been formed; for we must grant that they are merely two aspects and not isolated domains in the life of man.

Consciousness or the state of awareness is an internal and subjective process. Leibnitz says somewhere that if we could see the interior of our brain we would be able to observe particles jostling each other, but no feelings, no consciousness, but for all that an omniscient guide through the labyrinth of the nervous system could point out to us those commotions that are accompanied with consciousness. If consciousness (the purely subjective state) can not move, we are sure that these tiny brain motions (being the objective actualities of consciousness) produce modifications in the tissues which make muscles contract. The energy may be insignificant in amount but it acts in a place where, like the rudder in a ship, it possesses extraordinary efficiency.

Mr. Wilkinson assumes that will-force generates energy and hints at the possibility that all energy may be the product of such will-force, which proposition if tenable, 
would give a new lease of life to the old and scientifically discredited idea of a creation of the world from nothing by the fiat of a spiritual being called God. According to the monistic view organisms receive their energy from the storehouse of nature and return it by using it. All that has been supplied they surrender again in the form of motion and heat, and in this metabolism, this constant flux of matter in motion, consciousness is sustained not unlike the light of the flame in a lamp. In fact this metabolism constitutes the essential feature of organized life. Awareness renders us conscious of our own state of being and in this way it influences living creatures.

When we speak of consciousness we mean the subjective state of our physical condition and not the physiological process of the brain, and so we must insist that awareness in itself is no motion, but no one denies that the objective process in which it makes its appearance is as much a motion as are all other physiological occurrences; but the motory portion of brain work is insignificant in amount and its mechanical feature is not its aim or end.

Though consciousness, in itself, is not energy, the fact of consciousness is obviously the most significant event in the development of life. A strong unpleasant awareness of certain conditions is called pain. If pain were unconscious, living creatures would not mind it; and, vice versa, if pleasure were unconscious, living creatures would not attempt a pursuit of pleasure. Pain, the awareness of untoward states, and pleasure, the awareness of pleasing conditions, are the main factors that give direction to the motor apparatus of living beings, and if they were unconscious, the ends pursued would be different.

If a frog is placed in water and the water is slowly and gradually heated so as to render him unconscious of the pain of the increased heat (for it takes a definite amount of change to make a modification of conditions pass the 
threshold of apperception), the frog would allow himself to be cooked alive while a jump out of the pan could easily save him. If, however, the increase of heat is quick and intense, he flees from the place perhaps not on account of the danger but because he feels uncomfortable.

The tension of the subjective state which passes into action is called volition, and the accomplishment of a motion, an act of the will. Neither in volition nor in will is there any procreation of new energy, but simply an imparting of direction to energy held ready for the purpose.

When we speak of direction we mean a line of motion the position of which in space and its relation to a given line of reference are determinable by the measurement of angles. Direction in itself is not motion, but the imparting of direction, of course, is a motion. Here the case is analogous to consciousness. The position of the ship's rudder is a state or conditon, but to adjust the rudder according to requirements takes a certain, albeit a comparatively small, amount of energy.

Mr. Wilkinson speaks of the law of the conservation of matter and energy as a new-fangled doctrine, but he forgets that it is merely a new formulation of a very ancient and universally recognized law, the law of causation. The law of causation is a positive statement of the same truth proclaimed by the law of the conservation of matter and energy, which is simply a negative and therefore more cautious statement declaring that nothing can originate through or from nothing. Every new creation is merely a new combination of realities that existed before. In other words, the sum total of energy and matter remains the same, nothing (in either substance or force) can be lost, nothing in amuont can be added except it be taken from somewhere. Everything that is positively new is due to form.

It will be instructive to compare Mr. Wilkinson's view 
of the soul with Professor Ostwald's psychology of energetics as presented by him in the last number of The Monist. Professor Ostwald, too, thinks that there is some peculiar and special soul energy, but he would not countenance the idea of abolishing the law of the conservation of energy. He is antimaterialistic, but for all that he does not understand the point made by Leibnitz, viz., that consciousness is a purely subjective process, not a motion, nor anything material or objective. Ostwald is a monist, or at least tries to be one, but his monism consists in an omnienergeticism. Everything is energy, even the soul.

Professor Ostwald's line of argument is taken up by Professor Montague in an article published in the present issue of The Monist. He presents insurmountable diffculties which upset not only the interactionist theory but also the current psychology of parallelism, but his arguments presuppose the assumption of an independent existence of consciousness, and nowhere does he take into consideration the well established parallelism as commonly held by Herbart, Weber, Fechner, Wundt, Helmholtz, Hering, Ribot and others. None of them would deny that mental processes are in time, that they take place in succession, and also that their physiological activity is definitely localized in the brain. This view by no means excludes that consciousness itself, irrespective of its physiological substratum, is a purely subjective state, a mere condition of our awareness which as such has no motive power. The concatenation of physical processes in uninterrupted motion is always acting on energy, perhaps setting free stored-up energy, and nowhere is there a gap in the chain. Only some parts of the chain are such as to be possessed of peculiar states of awareness and though awareness is purely subjective, its presence is by no means indifferent. Concerning this latter point, however, I must grant that I am at variance with some supporters of the 
theory of parallelism, who claim that the flashing up of consciousness has as little effect as sparks of the engine thrown out of the chimney have upon the machinery which it sets in motion. And in a certain way this is true, for a motion of the muscular system takes place only when the motor nerve is stimulated, which means when the chain of mechanical connection remains uninterrupted. It is true enough that any motion can be executed with or without consciousness, but I would insist that whenever in novel conditions deliberation is needed, the presence or absence of consciousness would not be indifferent as to the final outcome of a decision.

The physiological details upon which the condition of awareness depends are not sufficiently known, but we may be sure that it is due to a process of organized interaction so arranged as to make a concentrated set of feelings become extraordinarily vivid, either by contrast or by convergence. Professor Montague has never alluded to the psychology of parallelism as it is set forth for instance by Hering in his famous essay On Memory, ${ }^{*}$ or as the author himself has treated the subject repeatedly in books and magazine articles. $\dagger$

Professor Montague quotes a number of views for the purpose of refuting them, but he nowhere cites the authorities of his opponents, (a habit shared also by Professor Ostwald, in some philosophical discussions at least) and so we cannot help having the impression that he exercises on self-fabricated men of straw. If similar views have been actually propounded by some scholars we are sure that their propositions were in some not unimportant details somewhat different.

Professor Montague accepts Leibnitz's criticism of the mechanistic theory and grants that consciousness is not a

* Chicago: The Open Court Publishing Company.

†For instance the first chapter in The Soul of Man, "Feeling and Motion." 
motion. The simplest solution that suggests itself to him is the assumption that it is potential energy. Motion (or kinetic energy) is visible, and if consciousness can not be seen, it might very well be that other kind of energy which being latent is not in evidence.

This is not a solution of the problem but a mere lack of appreciation of its significance. If consciousness is neither a material thing, nor a mechanical process, but an invisible subjective state, which could not be seen even if we could enter the brain where consciousness is being manufactured, it can not be a motion, but neither can it be a tension (i. e., a state of potential energy) ; and so Professor Montague's argument can only serve us as an instance that the philosophy of energetics breaks down in psychology.*

We will add that Professor Ostwald himself might have felt tempted to explain the soul as potential energy. We must confess that on reading his expositions on the subject we had the impression that he came dangerously near falling into the error, and it is not impossible that he was prevented from following this line of thought by his knowledge of physiological processes. He must have borne in mind that all states of feeling are accompanied by some nervous commotion and a state of rest in consciousness always coincides with a physiological state of rest. So long as nervous energy remains stored up in cerebral structures the psyche is at rest, and only the release of the stored-up energy, only a change of potential into kinetic energy, can indicate the condition of mental activity. It is obvious that mental activity means physiological work, not a passive condition of an uneventful storage.

Mr. Montague claims that some psychologists or philosophers propound the theory that mental phenomena

* Compare the editorial discussion of Ostwald's Energetics in the October number of The Monist, p. $5 \mathrm{If}$. 
are not in time and space, and perhaps that is so. We will here not ask who they are and what they really mean, but prefer to investigate the problem itself and ask the question, In what sense can it be said that mental phenomena are not in time and space?

It seems to me that nobody ever doubted that the process of thinking is temporal, in other words, that ideas, arguments, conclusions, decisions, etc., are being thought in time. The process of thinking begins at a certain moment and the chain of thoughts is consecutive. One idea follows another, and when the conclusion is reached the argument has come to an end. Consistently with these facts we must also grant that the thinking takes place somewhere within the body of the thinking person. We may be unable to localize the specific place in the brain, but for all that there is no one that would place it either nowhere or somewhere outside of the thinker's corporeal personality.

Yet if we do not speak of the process of thinking and bear in mind only the ideas that are being thought, we may very well insist that the ideas themselves do not depend upon time and space. Moral ideals for instance, such as justice, truthfulness, manliness, wisdom, etc., are eternal norms; just as the theorems of geometry and arithmetic are true anywhere and everywhere, and remain the same whether or not individual thinkers discover them in their brains.

They are not material, not corporeal, not concrete, for their very nature is generality which implies that they are independent of time and space.

Considering the fact that all rational thinking consists in utilizing generalizations and attempting to actualize for our own benefit the eternal norms of thought, we must grant that all abstract thought contains an element that is above time and space. All higher thought soars into the realms of the eternal, the universal, the superspatial rela- 
tions. Consciousness is subjective, and consciousness is closely interrelated with the physiological substratum of brain activity, but the purpose and aim of our thinking is a comprehension of concrete events, experiences, or things of any kind under the viewpoint of uniformities, the very nature of which is that they are independent of time and space. In this sense and in this sense alone thought may be said to be neither temporal nor spatial. It is the actualization of the purely formal, the intrinsically necessary relations of what Kant calls the $a$ priori, and Plato the eternal types of being,-ideas.

Our monistic view is neither materialistic, nor is it energistic. Matter is mere mass, or material, and energy, like all horsepower, is measurable in foot-pounds; it is not a deity to be spelled with a capital $E$. The problems of life and the ideals of mankind are not to be sought in the domains of either matter or energy, but are, all of them without any exception, questions of form. Hence the paramount importance of form; and for this reason we may call our monism "the philosophy of form."

A materialistic monism loses sight of the significance of form and, with it, of all intellectual, moral, artistic and religious treasures. We do not blame those who bear in mind the spiritual needs of mankind for shrinking from a onesided monism which ignores the most important facts of life and would rather accept some dualistic or mystical or agnostic explanation of the world than surrender the best and the holiest possessions of the heart, which are the only things in the world that impart worth to life. For this reason we take an interest in Mr. Wilkinson's efforts to establish his theory of consciousness, but while we appreciate that he does so in order to account for certain facts which a materialistic monism either denies or leaves unexplained, we can not accept his theory because his arguments appear to us insufficient and indeed untenable. We 
recognize in the pseudo-monistic system those very faults which he is anxious to avoid, and we establish the points he makes, viz., the significance of the soul as a principle of direction, and the possibility of man's responsibility including the importance of moral maxims.

Not the least advantage of our position, which is a new monism built upon a broad basis with special emphasis on the significance of form, consists in the fact that it renders possible a new interpretation of our religious traditions and thus it comes as a conciliation between science and religion; it comes not to destroy but to fulfil.

EDITOR. 